\title{
GMR
}

\section{Cloning and characterization of a novel betaine aldehyde dehydrogenase gene from Suaeda corniculata}

\author{
F.W. Wang ${ }^{1 *}$, M.L. Wang ${ }^{1 *}$, C. Guo ${ }^{1}$, N. Wang ${ }^{1}$, X.W. Li ${ }^{1}$, H. Chen ${ }^{1}$, \\ Y.Y. Dong ${ }^{1}$, X.F. Chen ${ }^{2}$, Z.M. Wang ${ }^{2}$ and H.Y. Li ${ }^{1}$ \\ ${ }^{1}$ College of Life Sciences, Engineering Research Center of the Chinese \\ Ministry of Education for Bioreactor and Pharmaceutical Development, \\ Jilin Agricultural University, Changchun, Jilin, China \\ ${ }^{2}$ Jilin Technology Innovation Center for Soybean Region, \\ Jilin Agricultural University, Changchun, Jilin, China \\ *These authors contributed equally to this study. \\ Corresponding author: H.Y. Li \\ E-mail: hyli99@163.com
}

Genet. Mol. Res. 15 (2): gmr.15027848

Received October 19, 2015

Accepted February 12, 2016

Published June 21, 2016

DOI http://dx.doi.org/10.4238/gmr.15027848

\begin{abstract}
Glycine betaine is an important quaternary ammonium compound that is produced in response to several abiotic stresses in many organisms. The synthesis of glycine betaine requires the catalysis of betaine aldehyde dehydrogenase (BADH), which can convert betaine aldehyde into glycine betaine in plants, especially in halotolerant plants. In this study, we isolated the full-length cDNA of BADH from Suaeda corniculata $(S c B A D H)$ using reverse transcriptase-polymerase chain reaction and rapid amplification of cDNA ends. Next, we analyzed the expression profile of $S c B A D H$ using real-time PCR. The results showed that $S c B A D H$ expression was induced in the roots, stems, and leaves of $S$. corniculata seedlings under salt and drought stress. Next, $S c B A D H$ was overexpressed in Arabidopsis, resulting in the transgenic plants exhibiting enhanced tolerance over wild-type plants under salt
\end{abstract}


and drought stress. We then analyzed the levels of glycine betaine and proline, as well as superoxide dismutase (SOD) activity, during salt stress in WT and transgenic Arabidopsis. The results indicated that overexpression of $S c B A D H$ produced more glycine betaine and proline, and increased SOD activity under $\mathrm{NaCl}$ treatment. Our results suggest that $S c B A D H$ might be a positive regulator in plants during the response to $\mathrm{NaCl}$.

Key words: BADH; Salt stress; Glycine betaine; Proline; SOD activity

\section{INTRODUCTION}

Plants are often exposed to various environmental stresses, such as drought, salinity, and low temperatures. For many important crops, salinity is a major factor that limits plants' geographical distribution and is responsible for significant reductions in yield and quality (Munns and Tester, 2008). Plants have developed a number of protective mechanisms to maintain normal cellular metabolism and prevent damage to cellular components (Wood et al., 1996). One common metabolic adaptation to salinity stress is the accumulation of osmoprotectants. One of these osmoprotectants, glycine betaine, is a bipolar quaternary ammonium compound, which accumulates in many plant species when subjected to various abiotic stresses (Rhodes and Hanson, 1993; Fan et al., 2012). Glycine betaine protects the plant from salt stress by maintaining the osmotic balance under various abiotic stresses (Wani et al., 2013) and by stabilizing the quaternary structure of complex proteins (Bernard et al., 1988). In photosynthetic systems, glycine betaine stabilizes the oxygen-evolving photosystem II complex and Rubisco at elevated salt concentrations (Zhou et al., 2008; Fan et al., 2012).

Betaine aldehyde dehydrogenase (BADH) catalyzes the final step in the synthesis of the osmoprotectant glycine betaine from choline (Nakamura et al., 1997; He et al., 2004). Many bacteria, plants, and animals accumulate glycine betaine under drought or salt stresses (Arakawa et al., 1990; Dong et al., 2006; Metris et al., 2014). The $B A D H$ gene has been cloned from Spinacia oleracea (Weretilnyk and Hanson, 1990), Atriplex hortensis (Xiao et al., 1995), Beta vulgaris (McCue and Hanson, 1992), Sorghum bicolor (Wood et al., 1996), Carthamus tinctorius (Wang et al., 2014), and Avicennia marina, and its functions are well characterized (Hibino et al., 2001). However, many researchers have demonstrated that some plant species, such as Arabidopsis, tobacco, tomato, and rice, do not accumulate glycine betaine (Huang et al., 2000; Sakamoto and Murata, 2000; Wani et al., 2013). This has generated interest in the metabolic engineering of the glycine betaine biosynthesis pathway as an approach to enhance salt resistance in salt-sensitive species (Chen et al., 2007). To date, several genes that catalyze the synthesis of glycine betaine, such as $C M O$ from spinach, CodA from Arthrobacter globiformis, BADH from spinach or sugar beet, and BetA and BetB from Escherichia coli, have been introduced into different plants (Shirasawa et al., 2006; Park et al., 2007). The transgenic plants produced less glycine betaine but, in some cases, showed significantly enhanced tolerance to salt or other stresses (Nuccio et al., 1999). In a previous investigation, Li et al. (2000) introduced the BADH gene from Atriplex hortensis into watercress. The transgenic plants grew normally on media containing $100 \mathrm{mM} \mathrm{NaCl}$ and survived on media containing $160 \mathrm{mM} \mathrm{NaCl}$. 
Suaeda corniculata, a member of the Chenopodiaceae, is native to the saline soil of northeastern China and is an important halophyte in China. Most plants will die quickly in the saline soil, but $S$. corniculata can survive, even in $\sim \mathrm{pH} 11$ saline soil. To determine the mechanism of resistance in $S$. corniculata, we cloned and characterized a novel $B A D H$ gene that could regulate abiotic stresses in other plants. Our results indicated that the expression of $S c B A D H$ could be induced by salt and PEG (Polyethylene glycol) treatments. The transgenic Arabidopsis also had improved salt and drought stress tolerances. Moreover, glycine betaine and proline, as well as SOD (Superoxide dismutase) activity, were maintained at higher levels in transgenic Arabidopsis than in wild-type (WT) plants under $\mathrm{NaCl}$ treatments. These results imply that ScBADH may play a significant role in plant salt stress.

\section{MATERIAL AND METHODS}

\section{Plant material and treatments}

Seeds of S. corniculata were collected from a saline soil area located in Baicheng, northeastern China. The seeds were sterilized and germinated on MS (Murashige and Skoog) medium supplemented with 3\% sucrose (w/v) and $0.7 \%$ agar $(\mathrm{w} / \mathrm{v})$ in a growth chamber for $8-10$ days at $22^{\circ} \mathrm{C}$. Seedlings were grown in pots filled with a 5:4:1 mixture of peat/forest soil/ vermiculite $(\mathrm{v} / \mathrm{v} / \mathrm{v})$ and perlite in a greenhouse at $24 / 16^{\circ} \mathrm{C}$ (day/night) with a $16-\mathrm{h}$ light $/ 8$ - $\mathrm{h}$ dark photoperiod and $60 \%$ relative humidity. Six-week-old plants of $S$. corniculata were treated with half-strength MS salt solution containing either $100 \mu \mathrm{M}$ ABA, $300 \mathrm{mM} \mathrm{NaCl}$ (salt stress treatment), or 10\% PEG8000 (w/v; drought stress treatment). The roots and leaves of these plants were collected at $0,6,12,24$, and $48 \mathrm{~h}$ after the initiation of the stress treatment. Plant material was placed directly into liquid nitrogen and stored at $-80^{\circ} \mathrm{C}$ until use.

\section{Isolation of $S c B A D H$ from $S$. corniculata by RT-PCR, and 5' and 3' RACE}

To isolate the $B A D H$ gene from $S$. corniculata, degenerate primers were designed based on the sequence of the conserved domain. The primer sequences were as follows: forward primer P1F: 5'-NTGYMGNYTNGGNCCNGTNA-3' and reverse primer P1R: 5'-CNCCNARYTCNCKNCCRAAN-3', where R denotes A or G; Y denotes C or T; K denotes $\mathrm{G}$ or $\mathrm{T}$; $\mathrm{B}$ denotes $\mathrm{C}, \mathrm{G}$ or $\mathrm{T}$; $\mathrm{H}$ denotes $\mathrm{A}, \mathrm{C}$ or $\mathrm{T}$; $\mathrm{V}$ denotes $\mathrm{A}, \mathrm{C}$ or $\mathrm{G}$; and $\mathrm{N}$ denotes $\mathrm{A}$, T, C or G. Total RNA was extracted from the leaves of $S$. corniculata treated with $200 \mathrm{mM}$ $\mathrm{NaCl}$ for $12 \mathrm{~h}$ using TRIzol reagent (Invitrogen, Beijing, China), and the RNA extracts were treated with RNase-free DNase according to the manufacturer protocol (Invitrogen). Final RNA $(1 \mu \mathrm{g})$ was used for first-strand cDNA synthesis and PCR according to the manufacturer protocol (Invitrogen). The reverse-transcription products were amplified by PCR under the following thermal cycle conditions: $94^{\circ} \mathrm{C}$ for $8 \mathrm{~min}$, followed by 35 cycles of $94^{\circ} \mathrm{C}$ for $30 \mathrm{~s}, 60^{\circ} \mathrm{C}$ for $30 \mathrm{~s}, 72^{\circ} \mathrm{C}$ for $60 \mathrm{~s}$, and $72^{\circ} \mathrm{C}$ for $8 \mathrm{~min}$. The PCR products were cloned into the pMD18-T vector (TaKaRa) and sequenced. Specific primers were then designed for rapid amplification of cDNA ends (RACE), based on the sequence information of the partial cDNA fragment, to obtain the full-length sequence of the gene. For 5'-RACE, two antisense gene-specific primers were designed (P2F, 5'-ATGTCGATCCCTATACCTTC-3' and P2R, 5'-GTCATACTGTCCCTTGCTAA-3'). Primers for 3'-RACE were P3F, 
5'-TACTGGAAGCAAGGTTATGG-3' and P3R, 5'-TCGTCCTGAGCATCTGAAGA-3'. The RACE reactions were performed according to the manufacturer protocol (Invitrogen), and the RACE products were cloned and sequenced. A full-length cDNA sequence was obtained by combining the 5'-RACE, the partial cDNA, and the 3'-RACE fragments. The full-length cDNA was amplified by PCR using the primers P4F (5'-ATGTCGATCCCTATACCTTC-3') and P4R (5'-TTAAGGAGACTTGTACCACC-3') under the following thermal cycler conditions: $94^{\circ} \mathrm{C}$ for $8 \mathrm{~min}$, followed by 35 cycles of $94^{\circ} \mathrm{C}$ for $45 \mathrm{~s}, 55^{\circ} \mathrm{C}$ for $45 \mathrm{~s}, 72^{\circ} \mathrm{C}$ for $90 \mathrm{~s}$, and $72^{\circ} \mathrm{C}$ for $8 \mathrm{~min}$. The resulting PCR products were cloned into the pMD18-T vector, and independently amplified clones were sequenced. These sequences were assembled to provide the full-length ScBADH cDNA. Homology analysis of the deduced protein ScBADH was performed, and phylogenetic analysis by the Neighbor-Joining method was undertaken using ClustalW and the MEGA 4.1 software.

\section{Quantitative real-time PCR analysis}

qRT-PCR was used to determine the level of $S c B A D H$ expression in seedlings of $S$. corniculata. An aliquot $(1 \mu \mathrm{g})$ of total RNA was reverse-transcribed using $1 \mu \mathrm{L}$ oligo (dT) 18 primer $(50 \mathrm{uM}), 1.0 \mu \mathrm{L}$ dNTPs $(10 \mathrm{mM}), 4 \mu \mathrm{L} 5 \mathrm{X}$ M-MLV buffer, $1 \mu \mathrm{L}$ RNase inhibitor $(40 \mathrm{U} / \mu \mathrm{L}$ ), and $1 \mu \mathrm{L}$ murine reverse-transcriptase M-MLV (Promega; $200 \mathrm{U} /$ $\mu \mathrm{L})$ according to the manufacturer protocol. The PCR was performed in a total volume of $25 \mu \mathrm{L}$ with 30 cycles. The primers used were designed with Primer Premier 5.0 and Oligo 6 programs to allow for the amplification of $\sim 150 \mathrm{bp}$ products. The following gene-specific primers were used: P5F (5'-CCTTGGAACTTGGAGGTAAA-3') and P5R (5'-TTCCGTTCGGCAGATGTTGT-3'). Actin-F (5'-GGAGAGAACCCATCAAACG-3') and Actin-R (5'-TCCAGAAGTAGCAGCCCA A-3') were used to amplify the actin gene as an internal control.

qRT-PCR was performed on a Mx3000P instrument (Stratagene), with SYBR-Green detection (Quant RT-PCR Kit, Tiangen Biotechnology), according to the manufacturer instructions. Thermal cycler conditions were: $2 \mathrm{~min}$ at $95^{\circ} \mathrm{C}$ followed by 40 cycles of $15 \mathrm{~s}$ at $95^{\circ} \mathrm{C}, 15 \mathrm{~s}$ at $57^{\circ} \mathrm{C}$, and $30 \mathrm{~s}$ at $72^{\circ} \mathrm{C}$. The cDNA was analyzed three times, after which the average threshold cycle $(\mathrm{Ct})$ was calculated for each sample. Standard curves were established for all investigated genes using a series of amplicon dilutions. The relative expression levels were calculated as $2^{-(\Delta C \text { t of treatment }-\Delta \mathrm{Ct} \text { of control) }}$.

\section{Construction of plant expression vectors and Arabidopsis transformation}

The complete open reading frame (ORF) of $S c B A D H$ was amplified with the primers P6F (5'-AAAAAGCAGGCTATGAGTGGCATTCTTCTTC-3') and P6R (5'-AGAAAGCTGGGTTTAGAAGATCTTCAAGAGCA-3') under the following thermal cycler conditions: $94^{\circ} \mathrm{C}$ for $8 \mathrm{~min}$, followed by 35 cycles of $94^{\circ} \mathrm{C}$ for $30 \mathrm{~s}, 52^{\circ} \mathrm{C}$ for $30 \mathrm{~s}, 72^{\circ} \mathrm{C}$ for $80 \mathrm{~s}$, and $72^{\circ} \mathrm{C}$ for $8 \mathrm{~min}$. The PCR products were purified and cloned into the pDONR221 entry vector via the BP reaction (The recombination reaction between an attB-flanked DNA fragment and an attP-containing donor vector, Gateway ${ }^{\circledR}$ Technology, Invitrogen). For $S c B A D H$ cDNAs, pENTRY clones from individual bacterial colonies were used subsequently in LR reactions (The recombination reaction between an at $t \mathrm{~L}$-containing entry clone and an 
attR-containing destination vector, Gateway ${ }^{\circledR}$ Technology, Invitrogen) with the expression vector pCB35sR1R2 to generate pCB35s-ScBADH (Sambrook et al., 1989). The pCB35sScBADH plasmid was introduced into Agrobacterium tumefaciens EHA105. The plant overexpression vector of $\mathrm{ScBADH}, \mathrm{pCB} 35 \mathrm{~s}-\mathrm{ScBADH}$, was then introduced into Arabidopsis thaliana (ecotype Col-0) by the floral-dip method (Clough and Bent, 1998).

\section{Analysis of stress tolerance of transgenic plants}

For the phenotype assay, seeds of WT and transgenic Arabidopsis (L25 and L27) were germinated on MS agar medium (Murashige and Skoog, 1962) under a 16-h/8-h light/ dark photoperiod at $22^{\circ} \mathrm{C}$ with $50 \%$ relative humidity. After $6 \mathrm{~d}$, young seedlings were transplanted to fresh MS agar medium supplemented with, $0 \mathrm{mM} \mathrm{NaCl}, 200 \mathrm{mM} \mathrm{NaCl}, 1.0$ $\mu \mathrm{M}$ ABA or $10 \%$ PEG 8000 . The seedlings were maintained at $22^{\circ} \mathrm{C}$, and their growth was monitored for $15 \mathrm{~d}$. The experiment was repeated three times. Photographs were taken of 20-day-old plants.

\section{Measurements of proline content and SOD activity}

Ten-day-old seedlings of WT and transgenic Arabidopsis were transplanted to fresh MS agar media supplemented with one of four salt solutions $(0,100,150$, and $200 \mathrm{mM} \mathrm{NaCl})$ for 15 days. Proline was extracted from $0.1 \mathrm{~g}$ freeze-dried seedlings and spectrophotometrically determined using the acid ninhydrin method described by Hanson et al. (1979). To analyze SOD activity, fine powder of seedlings was resuspended in $50 \mathrm{mM}$ potassium phosphate $\mathrm{pH}$ 7.8) containing $0.1 \mathrm{mM}$ EDTA and 1\% PVP, and then centrifuged at 12,000 $\mathrm{g}$ for $15 \mathrm{~min}$ at $4^{\circ} \mathrm{C}$. For the assay, $3 \mathrm{~mL}$ of the reaction mixture containing $50 \mathrm{mM}$ potassium phosphate $(\mathrm{pH}$ 7.8). $0.1 \mathrm{mM}$ EDTA, $1 \%$ PVP, $13 \mathrm{mM}$ methionine, $75 \mu \mathrm{M}$ nitroblue tetrazolium (NBT), and enzyme extract was added to $2 \mu \mathrm{M}$ riboflavin. One unit of SOD activity was defined as the amount of enzyme required to inhibit $50 \%$ NBT photoreduction. The mixtures were illuminated in glass test tubes for $10 \mathrm{~min}$, and the absorbance at $560 \mathrm{~nm}$ was quickly determined with a spectrophotometer. The SOD activity was expressed as U/g of seedlings.

\section{Glycine betaine analysis}

One-week-old WT and transgenic Arabidopsis seedlings were transplanted on MS agar medium containing $200 \mathrm{mM} \mathrm{NaCl}$. Plant materials were collected and ground after 0 , $3,6,9$, and 12 days. The glycine betaine content was determined following the procedure described by Grieve and Grattan (1983) with minor modifications. Dried and finely powdered plant materials $(0.3 \mathrm{~g})$ were shaken with $20 \mathrm{~mL}$ of deionized water for $24 \mathrm{~h}$ at $25^{\circ} \mathrm{C}$. The extracts were diluted 1:1 with $2 \mathrm{~N} \mathrm{H}_{2} \mathrm{SO}_{4}$. Aliquots of $0.5 \mathrm{~mL}$ were placed in test tubes and cooled in ice water for $1 \mathrm{~h}$ before a cold $\mathrm{KI}-\mathrm{I}_{2}$ reagent $(200 \mu \mathrm{L})$ was added. The tubes were stored at $0-4^{\circ} \mathrm{C}$ for $16 \mathrm{~h}$ and then centrifuged at $12,000 \mathrm{~g}$ for $15 \mathrm{~min}$ at $4^{\circ} \mathrm{C}$. The supernatant was aspirated. The periodate crystals were dissolved in $5 \mathrm{~mL} \mathrm{1,2-dichloroethane.} \mathrm{After} 2.5 \mathrm{~h}$, the absorbance was read at $365 \mathrm{~nm}$ with a UV-visible spectrophotometer. Reference standards of glycine betaine $(20-200 \mathrm{~g} / \mathrm{mL})$ were used for calibration and to determine the glycine betaine concentrations in samples. 


\section{Statistical analysis}

Each experiment was performed in triplicate $(\mathrm{N}=5$ for expression analyses and $\mathrm{N}=4$ for physiological analyses). Statistical significance analyses were performed using a univariate analysis of variance (Duncan's test, $\mathrm{P}<0.05$; SPSS for windows, version 13.0).

\section{RESULTS}

\section{Cloning of $S c B A D H$ from S. corniculata}

The full-length cDNA of $S c B A D H$ was obtained by RT-PCR and RACE. The $S c B A D H$ cDNA contained a 1500-bp ORF encoding a protein of 500 amino acids with a theoretical molecular mass of $54.7 \mathrm{kDa}$. Phylogenetic analysis (Figure 1A) showed that ScBADH formed a clade with the most closely related plant BADH homologs. The highest similarity of $94 \%$ was found with BADH from Suaeda liaotungensis, a salt-tolerant grass. ScBADH also showed high similarity to BADH from Amaranthus hypochondriacus (93.6\%), Halostachys caspica (91\%), B. vulgaris (89\%), and Gossypium hirsutum (87\%). The functional domains of the amino acid sequence encoded by $S c B A D H$ were analyzed (Figure 1B) and found to include the conservative region of the catalytic domain, which is conserved in other BADHs. These functional domains play important roles in the plant responses to abiotic stresses.

\section{$S c B A D H$ transcript analysis in $S$. corniculata}

To characterize the function of $S c B A D H$, we investigated the pattern of $S c B A D H$ expression under drought (10\% PEG8000), salt (300 $\mathrm{mM} \mathrm{NaCl})$, and abscisic acid (ABA) $(100 \mu \mathrm{M})$ treatments using quantitative real-time PCR. The results indicated that $S c B A D H$ gene expression was induced in roots, stems, and leaves by ABA, drought, and salt treatments (Figure 2). Accumulation of the $S c B A D H$ transcript in roots was maximal at $24 \mathrm{~h}$ under salt and drought stress, and then decreased slowly at $48 \mathrm{~h}$. However, during ABA treatment, peak $S c B A D H$ expression was observed at $12 \mathrm{~h}$. In stems, the $S c B A D H$ transcript level was maximal at $24 \mathrm{~h}$ and then decreased at $48 \mathrm{~h}$ during salt treatment. Under ABA and drought treatments, peak $S c B A D H$ expression was observed at $12 \mathrm{~h}$. In leaves, accumulation of the $S c B A D H$ transcript followed the same time course observed in the stems, indicating that $S c B A D H$ expression in roots under salt stress differs from that in stems and leaves.

\section{Overexpression of $S c B A D H$ increases salt and drought tolerance in transgenic Arabidopsis}

To further characterize the function of ScBADH, we obtained several transgenic Arabidopsis lines that overexpress $S c B A D H$, driven by the CaMV 35S promoter. The level of $S c B A D H$ expression in the transgenic Arabidopsis lines was analyzed by relative quantitative RT-PCR. Lines 25 (L25) and 27 (L27) showed slightly higher levels of ScBADH transcripts; therefore, they were used in the following study (data not presented). Seeds of both WT and transgenic lines were germinated on MS agar medium for 6 days, and the seedlings were then transferred to MS medium containing $0 \mathrm{mM} \mathrm{NaCl}, 200 \mathrm{mM} \mathrm{NaCl}, 1.0 \mu \mathrm{M} \mathrm{ABA}$, or $10 \%$ 
A

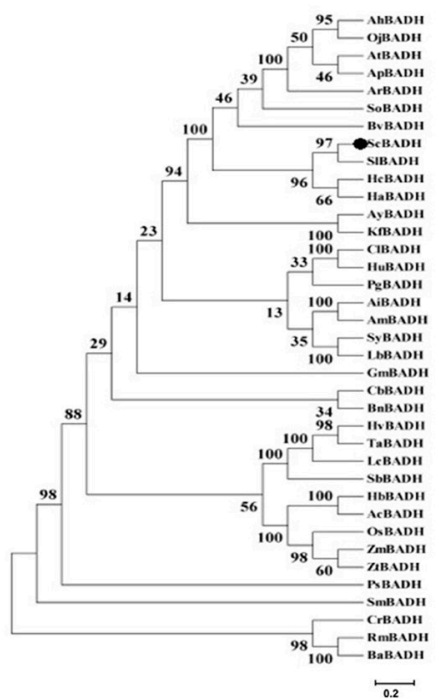

B

catalytic domain

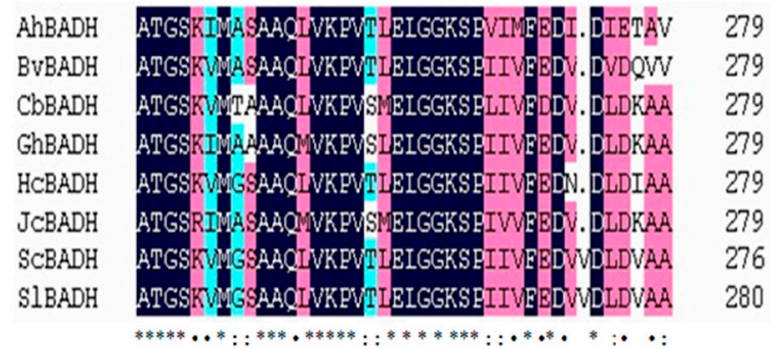

Figure 1. A. Phylogenetic tree of betaine aldehyde dehydrogenase $(B A D H)$ genes includes the Suaeda corniculata $B A D H$ gene and $B A D H$ genes from 36 other plant species: Suaeda liaotungensis (SIBADH; AAL33906.1), Atriplex hortensis (AhBADH; ABF72123.1), Ophiopogon japonicus (OjBADH; ABG34273.1), Atriplex tatarica (AtBADH; ABQ18317.1), Atriplex prostrata (ApBADH; AAM08913.1), Spinacia oleracea (SoBADH; AAB41696.1), Beta vulgaris (BvBADH; BAE07176.1), Halostachys caspica (HcBADH; ABO45931.1), Haloxylon ammodendron (HaBADH; ACS96437.1), Kalidium foliatum (KfBADH; ABI95806.1), Chrysanthemum lavandulifolium (ClBADH; AAY33872.1); Atriplex micrantha (AmBADH; ABM97658.1), Lycium barbarum (LbBADH; ACQ99195.1), Glycine max (GmBADH; ADN03184.1); Chorispora bungeana (CbBADH; AAV67891.2), Brassica napus (BnBADH; AAQ55493.1); Triticum aestivum (TaBADH; AAL05264.1), Leymus chinensis (LcBADH; BAD86757.1); Sorghum bicolor (SbBADH; AAC49268.1); Arabidopsis thaliana (AtBADH; NP 190400.1); Picea sitchensis (PsBADH; ABK24463.1); Zoysia tenuifolia (ZtBADH; BAD34952.1); Zea mays (ZmBADH; NP_001157804.1); Solanum lycopersicum (SIBADH; AAX73303.1); Agropyron cristatum (AcBADH; ACZ67850.1); Chlamydomonas reinhardtii (CrBADH; XP_001699134.1); Rhizobium etli (RmBADH; EGE60174.1); and Burkholderia ambifaria (BaBADH; YP 001809915.1). Dot indicates the S. corniculata BADH gene. Protein sequences were aligned with ClustalW and the phylogenetic tree was constructed using MEGA 4.1. Bootstrap percentages are presented at dendrogram branch points. B. Multiple alignment of the deduced amino acid sequence of $S c B A D H$ with seven BADHs from other plant species. Alignments of segments containing highly conserved motifs among the eight BADHs are shown. Protein abbreviations are as follows: Ah (Amaranthus hypochondriacus); Bv (Beta vulgaris); Cb (Chorispora bungeana); Gh (Gossypium hirsutum); Hc (Halostachys caspica); Jc (Jatropha curcas); Sl (Suaeda liaotungensis); Sc (Suaeda corniculata). The sequences were aligned using ClustalW. A catalytic domain (indicated by a line above the alignment) has been proposed in the conserved segment. Asterisks indicate identical amino acid residues, colons indicate amino acids with high similarity, periods indicate amino acids with low similarity, and dashes indicate gaps. The line shows the score of the catalytic domain. 
PEG8000. The results showed that the WT seedlings withered and the leaves became chlorotic, whereas the transgenic seedlings were only slightly affected and could survive under $\mathrm{NaCl}$ and PEG treatments (Figure 3). The transgenic and WT plants showed no significant differences during $\mathrm{ABA}$ treatment (Figure 3). These results suggest that the overexpression of $S c B A D H$ in Arabidopsis increases tolerance to salt and drought stress, especially salt stress.
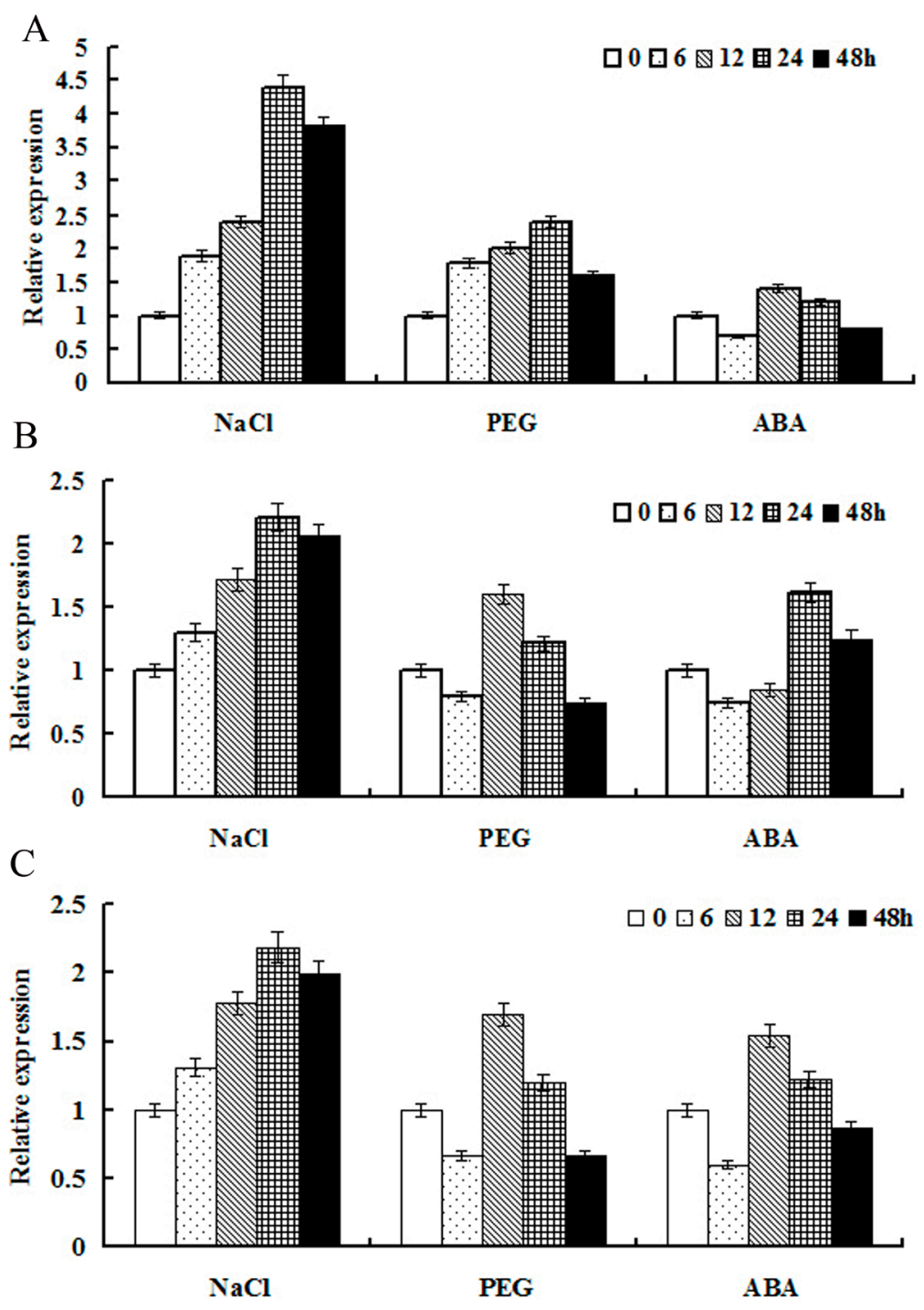

Figure 2. Transcript patterns of the Suaeda corniculata betaine aldehyde dehydrogenase $(S c B A D H)$ gene in seedlings in response to different stresses. A. Transcript level of $S c B A D H$ in the roots under salt $(300 \mathrm{mM} \mathrm{NaCl})$, dehydration $(30 \% \mathrm{PEG})$, and abscisic acid $(\mathrm{ABA} ; 100 \mu \mathrm{M})$ treatment for $0,6,12$, and $24 \mathrm{~h}$. B. Transcript level of $S c B A D H$ in the stems under salt $(300 \mathrm{mM} \mathrm{NaCl})$, dehydration $(30 \% \mathrm{PEG})$, and $\mathrm{ABA}(100 \mu \mathrm{M})$ treatment for 0,6 , 12 , and $24 \mathrm{~h}$. C. Transcript level of $S c B A D H$ in the leaves under salt ( $300 \mathrm{mM} \mathrm{NaCl})$, dehydration $(30 \% \mathrm{PEG})$, and $\mathrm{ABA}(100 \mu \mathrm{M})$ treatment for $0,6,12$, and $24 \mathrm{~h}$. Values are reported as means $\pm \mathrm{SD}(\mathrm{N}=5)$. 
WT

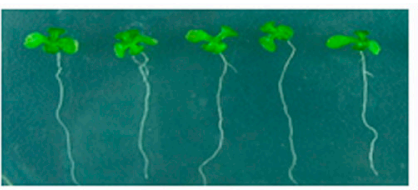

b
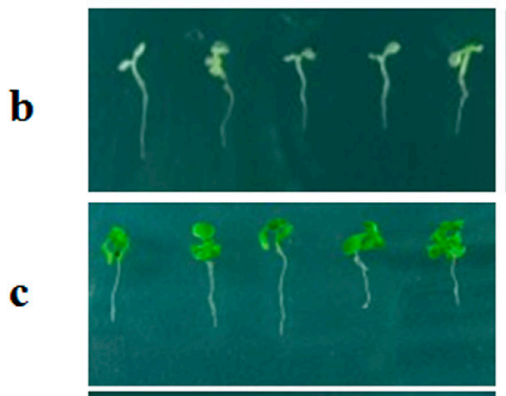

d

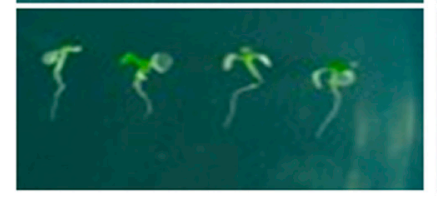

L25
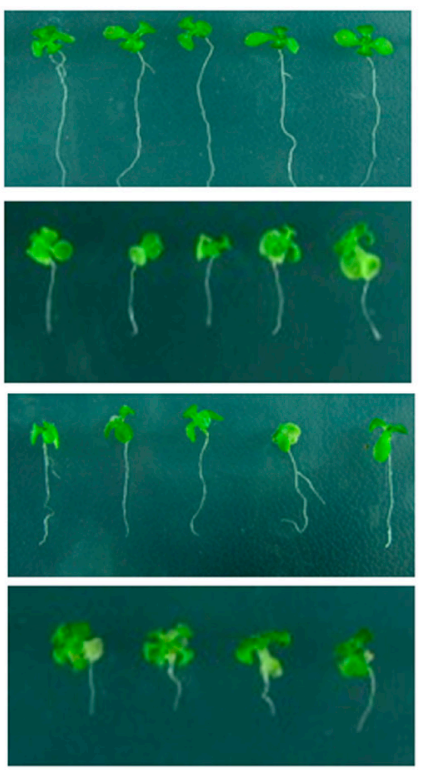

L27
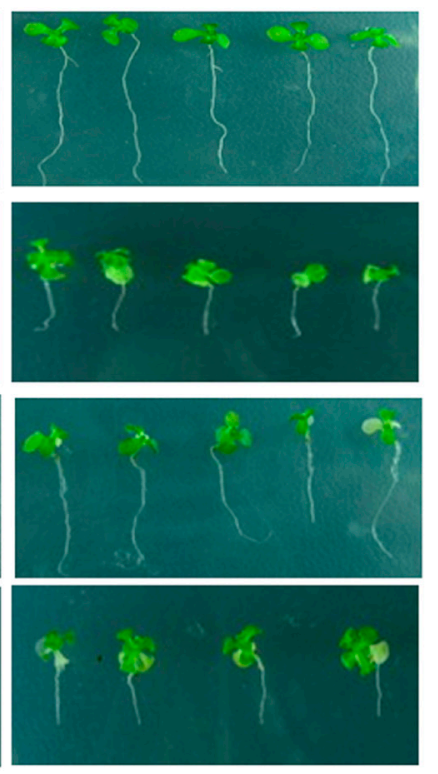

Figure 3. Analysis of stress tolerance in Arabidopsis seedlings overexpressing Suaeda corniculata betaine aldehyde dehydrogenase $(S c B A D H)$. Seedlings were photographed 8 days after transplantation. Transgenic stressed seedlings L25 and L27 showed a higher survival rate compared with the wild-type (WT) controls. Arabidopsis seedlings were grown in standard culture media for 1 week (when the first two true leaves had already emerged) before being transferred to media containing $0 \mathrm{mM}$ (a), $200 \mathrm{mM} \mathrm{NaCl}$ (b), $1.0 \mu \mathrm{M} \mathrm{ABA}(\mathbf{c})$, or $10 \%$ PEG8000 (d).

\section{Transgenic plants exhibit higher amounts of proline and glycine betaine under salt stress}

To determine why transgenic lines showed enhanced tolerance under salt stress, we analyzed the levels of glycine betaine and proline, as well as SOD activity. First, we analyzed proline levels and SOD activity under different salt concentrations. Under non-salt stressed conditions, there was minimal difference between the WT and transgenic plants (Figure 4A and B). The proline levels increased with increasing salt concentrations; however, proline levels were higher in L25 and L27 seedlings than in WT seedlings (Figure 4A and B). Although SOD activity decreased in WT and transgenic plants during salt stress, SOD activity in L25 and L27 plants remained higher than in WT plants (Figure 4A and B). Based on the changes in proline levels and SOD activity at various salt concentrations, we selected $200 \mathrm{mM} \mathrm{NaCl}$ for subsequent glycine betaine analysis. During treatment with $\mathrm{NaCl}$, the glycine betaine content initially increased with time, but then declined slowly after 6 days. The level of glycine betaine was higher in transgenic Arabidopsis seedlings than in WT seedlings (Figure 4C). These data indicate that $\mathrm{ScBADH}$ is involved in salt stress and that it may play a positive role in salt tolerance. 


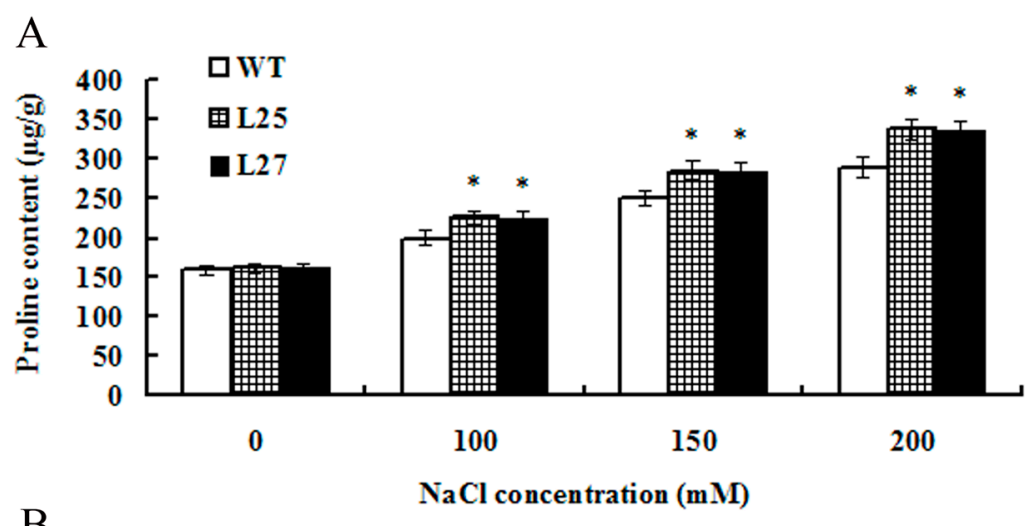

B
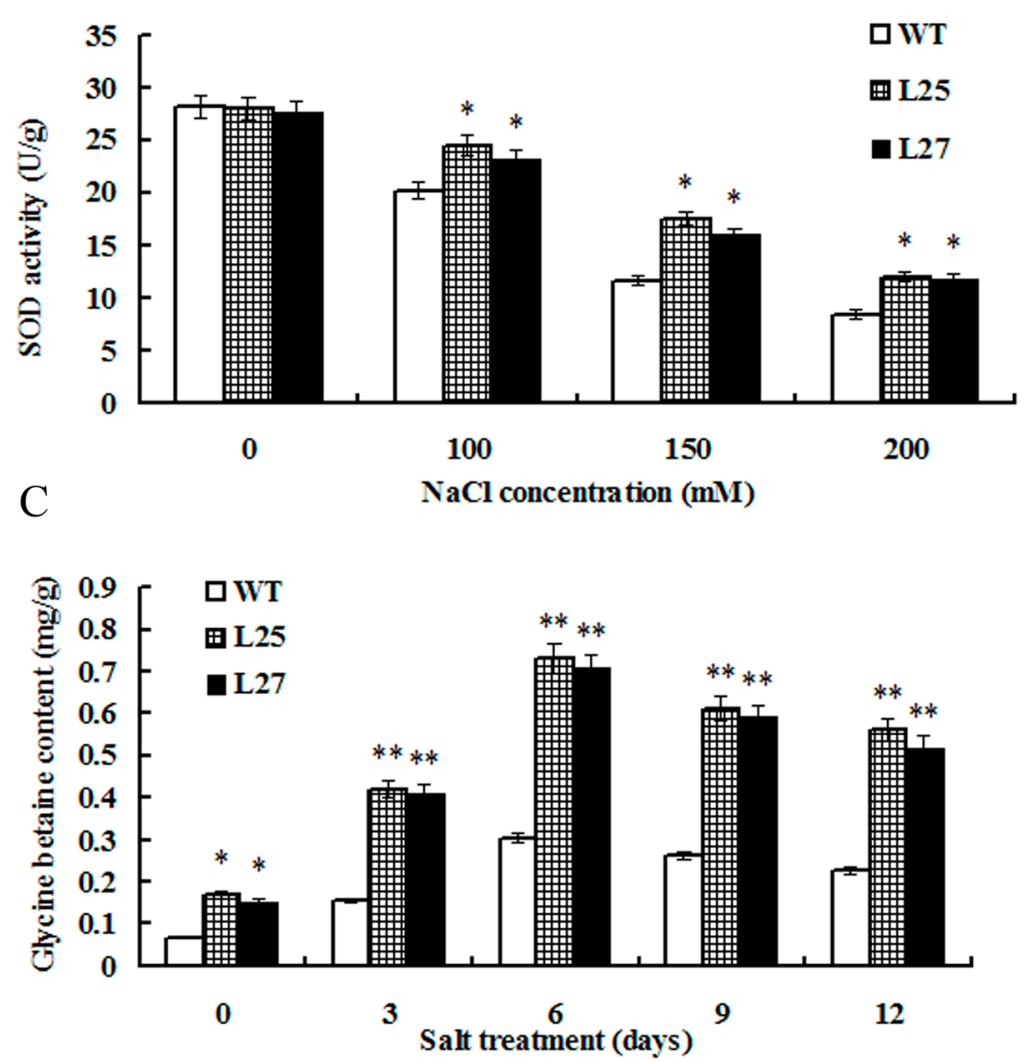

Figure 4. Physiological analyses of transgenic Arabidopsis plants containing Suaeda corniculata betaine aldehyde dehydrogenase $(S c B A D H)$ gene under salt stress. A. Proline levels were measured after 15 days under various $\mathrm{NaCl}$ concentrations. B. Superoxide dismutase (SOD) activity was measured after 15 day under various $\mathrm{NaCl}$ concentrations. C. Glycine betaine levels were measured at different times during treatment with $200 \mathrm{mM} \mathrm{NaCl}$ treatment. Physiological levels in transgenic lines were compared with those in the control under various stresses treatments and at different time points. Data were obtained from three independent experiments and are reported as means $\pm \mathrm{SD}(\mathrm{N}=4), \mathrm{P}<0.05$. WT: non-transgenic controls; L25, L27: transgenic lines overexpressing ScBADH. 


\section{DISCUSSION}

BADH proteins have been identified in microorganisms and in mammalian liver cells, where they act as osmoregulation agents and aldehyde dehydrogenase E3 isozymes. BADH converts betaine aldehyde into glycine betaine in some halotolerant plants. $B A D H$ genes in plants may form a small multi-gene family, such as in barley, which has two or three $B A D H$ genes (Liu et al., 2010). Two BADH genes were cloned from Sorghum vulgare, A. marina, and Atriplex triangularis (Wood et al., 1996; Hibino et al., 2001; He et al., 2004). However, the expression profiles and subcellular location of BADH family members differ. In this study, a novel BADH encoding gene, $S c B A D H$, was isolated from the halophyte $S$. corniculata. The pattern of $S c B A D H$ expression was analyzed in roots, stems, and leaves under various environmental stresses (Figure 2). The results showed that $S c B A D H$ transcripts could be induced by $\mathrm{ABA}, \mathrm{PEG}$, and especially, $\mathrm{NaCl}$ treatments. These results are similar to those obtained in rice but different to those obtained in Arabidopsis (Niu et al., 2007; Missihoun et al., 2011), indicating that $S c B A D H$ may be involved in signal transduction in response to salt in $S$. corniculata.

Missihoun et al. (2011) showed that young and adult plants lacking ALDH10A8 transcripts were drought and salt sensitive. Similar results were found in sweet potato, in which those expressing spinach BADH had improved stress tolerance (Fan et al., 2012). In our study, we analyzed transgenic Arabidopsis plants expressing $S c B A D H$ under NaCl, PEG, and ABA treatments. There were no significant differences between the transgenic and WT plants under ABA treatment. ABA plays a central role in the control of responses to stresses, such as salinity (Pons et al., 2013). However, our results and those of Meng et al. (2001) indicate that transgenic plants overexpressing BADH exhibit enhanced tolerance to salt and drought treatments, but not to ABA. Furthermore, transgenic Arabidopsis exhibited enhanced tolerance during $\mathrm{NaCl}$ treatment in this study. Interestingly, transgenic plants overexpressing ScVP (Encoding a vacuolar inorganic pyrophosphatase from the halophyte) showed similar results, such that a significant phenotype appeared under higher salt concentrations (Liu et al., 2011). These findings imply that ScBADH may acts as a positive regulator of salt resistance in plants. Moreover, non-transgenic plants exhibited minimal growth on MS medium containing $10 \%$ PEG8000, whereas transgenic plants grew normally (Figure 3 ). These results indicate that $S c B A D H$ might regulate plant responses to salt and drought stress through an ABAindependent pathway.

In recent reports, glycine betaine accumulation in transgenic sweet potatoes following heterologous overexpression of the $S o B A D H$ gene dramatically improved the tolerance to salt, cold, and oxidative stresses (Fan et al., 2012). Our data are consistent with this phenotype during salt stress. This raised the question of that why higher BADH level could improve plant salt, cold and oxidative stresses). The accumulation of proline and increased activity of antioxidants, such as SOD, APX (Ascorbate peroxidase), and CAT (Catalase), are known to play important roles in the induction of salt tolerance (Abraham and Dhar, 2010; Fan et al., 2012). Our data showed that proline levels increased during salt stress, especially in transgenic plants (Figure 4A), which is consistent with findings in transgenic plants overexpressing EsMcsul from Eutrema salsugineum (Zhou et al., 2015). SOD activity declined after $\mathrm{NaCl}$ treatment, but to a lesser extent in transgenic plants than in WT plants (Figure 4B). Our data also revealed that glycine betaine accumulation is induced by salt treatment. The protective role 
of betaine may lie in its strong stabilizing effects on the structure and function of the oxygenevolving PSII complex (Ohnishi and Murata, 2006; Zhou et al., 2008). This is consistent with transgenic plants containing high betaine levels having enhanced tolerance to abiotic stress.

In conclusion, we cloned a novel $B A D H$ gene from $S$. corniculata and found that its expression could be induced by salt and drought stress. Transgenic Arabidopsis overexpressing the $S c B A D H$ gene had enhanced salt tolerance under $\mathrm{NaCl}$ treatment. Furthermore, the levels of proline and glycine betaine, as well as SOD activity, increased in transgenic plants during salt stress. These results demonstrate that $S c B A D H$ might be a positive regulator in plants during salt treatment.

\section{Conflicts of interest}

The authors declare no conflict of interest.

\section{ACKNOWLEDGMENTS}

Research supported by the Special Program for Research of Transgenic Plants (\#2014ZX08010-002), and the National Natural Science Foundation of China (\#31271746, \#31201144 and \#31401403).

\section{REFERENCES}

Abraham G and Dhar DW (2010). Induction of salt tolerance in Azolla microphylla Kaulf through modulation of antioxidant enzymes and ion transport. Protoplasma 245: 105-111. http://dx.doi.org/10.1007/s00709-010-0147-3

Arakawa K, Katayama M and Takabe T (1990). Levels of betaine and betaine aldehyde dehydrogenase activity in the green leaves, and etiolated leaves and roots of barley. Plant Cell Physiol. 31: 797-803.

Bernard T, Ayache M and Le Rudulier D (1988). Restoration, by glycine betaine, of growth and enzyme activities of Escherichia coli Lac-mutants. C. R. Acad. Sci. III 307: 99-104.

Chen Z, Cuin TA, Zhou M, Twomey A, et al. (2007). Compatible solute accumulation and stress-mitigating effects in barley genotypes contrasting in their salt tolerance. J. Exp. Bot. 58: 4245-4255. http://dx.doi.org/10.1093/jxb/erm284

Clough SJ and Bent AF (1998). Floral dip: a simplified method for Agrobacterium-mediated transformation of Arabidopsis thaliana. Plant J. 16: 735-743. http://dx.doi.org/10.1046/j.1365-313x.1998.00343.x

Dong HB, Guan RZ, Zhang HS and Huang J (2006). Molecular cloning and characterization of a betaine-aldehyde dehydrogenase gene in Descurainia sophia. Mol. Plant Breed. 4: 209-215.

Fan W, Zhang M, Zhang H and Zhang P (2012). Improved tolerance to various abiotic stresses in transgenic sweet potato (Ipomoea batatas) expressing spinach betaine aldehyde dehydrogenase. PLoS One 7: e37344. http://dx.doi. org/10.1371/journal.pone.0037344

Grieve CM and Grattan SR (1983). Rapid assay for determination of water soluble quaternary ammonium compounds. Plant Soil 70: 303-307. http://dx.doi.org/10.1007/BF02374789

Hanson AD, Nelsen CE, Pedersen AR and Everson EH (1979). Capacity for proline accumulation during water stress in barley and its implications for breeding for drought resistance. Crop Sci. 19: 489-493. http://dx.doi.org/10.2135/cro psci1979.0011183X001900040015x

He XL, Hou XL, Wu JZ, Liu GH, et al. (2004). Molecular cloning and sequence analysis of betaine-aldehyde dehydrogenase (BADH) in Atriplex triangularis. J. Nanjing Agric. Univ. 27: 15-19.

Hibino T, Meng Y-L, Kawamistsu Y, Uehara N, et al. (2001). Molecular cloning and functional characterization of two kinds of betaine accumulating mangrove Avicennia marina (Forsk.) Vierh. Plant Mol. Biol. 45: 353-363. http:// dx.doi.org/10.1023/A:1006497113323

Huang J, Hirji R, Adam L, Rozwadowski KL, et al. (2000). Genetic engineering of glycinebetaine production toward enhancing stress tolerance in plants: metabolic limitations. Plant Physiol. 122: 747-756. http://dx.doi.org/10.1104/ pp.122.3.747 
Li YX, Chang FQ, Du LQ, Guo BH, et al. (2000). Genetic transformation of watercress with a gene encoding for betaine aldehyde dehydrogenase (BADH). Acta Bot. Sin. 42: 480-484.

Liu J, Zeng HM, Li X, Xu LX, et al. (2010). Isolation and characterization of the betaine aldehyde dehydrogenase gene in Ophiopogon japonicus. Open Biotechnol. J. 4: 18-25. http://dx.doi.org/10.2174/1874070701004010018

Liu L, Wang Y, Wang N, Dong YY, et al. (2011). Cloning of a vacuolar $\mathrm{H}^{+}$)-pyrophosphatase gene from the halophyte Suaeda corniculata whose heterologous overexpression improves salt, saline-alkali and drought tolerance in Arabidopsis. J. Integr. Plant Biol. 53: 731-742.

McCue KF and Hanson AD (1992). Salt-inducible betaine aldehyde dehydrogenase from sugar beet: cDNA cloning and expression. Plant Mol. Biol. 18: 1-11. http://dx.doi.org/10.1007/BF00018451

Meng YL, Wang YM, Zhang B and Nii N (2001). Isolation of a choline monooxygenase cDNA clone from Amaranthus tricolor and its expressions under stress conditions. Cell Res. 11: 187-193. http://dx.doi.org/10.1038/sj.cr.7290085

Metris A, George SM, Mulholland F, Carter AT, et al. (2014). Metabolic shift of Escherichia coli under salt stress in the presence of glycine betaine. Appl. Environ. Microbiol. 80: 4745-4756. http://dx.doi.org/10.1128/AEM.00599-14

Missihoun TD, Schmitz J, Klug R, Kirch HH, et al. (2011). Betaine aldehyde dehydrogenase genes from Arabidopsis with different sub-cellular localization affect stress responses. Planta 233: 369-382. http://dx.doi.org/10.1007/s00425$\underline{010-1297-4}$

Munns R and Tester M (2008). Mechanisms of salinity tolerance. Annu. Rev. Plant Biol. 59: 651-681. http://dx.doi. org/10.1146/annurev.arplant.59.032607.092911

Murashige T and Skoog F (1962). A revised medium for rapid growth and bioassays with tobacco cultures. Physiol. Plant. 15: 473-497. http://dx.doi.org/10.1111/j.1399-3054.1962.tb08052.x

Nakamura T, Yokota S, Muramoto Y, Tsutsui K, et al. (1997). Expression of a betaine aldehyde dehydrogenase gene in rice, a glycinebetaine nonaccumulator, and possible localization of its protein in peroxisomes. Plant J. 11: 11151120. http://dx.doi.org/10.1046/j.1365-313X.1997.11051115.x

Niu X, Zheng W, Lu BR, Ren G, et al. (2007). An unusual posttranscriptional processing in two betaine aldehyde dehydrogenase loci of cereal crops directed by short, direct repeats in response to stress conditions. Plant Physiol. 143: 1929-1942. http://dx.doi.org/10.1104/pp.107.095752

Nuccio ML, Rhodes D, McNeil SD and Hanson AD (1999). Metabolic engineering of plants for osmotic stress resistance. Curr. Opin. Plant Biol. 2: 128-134. http://dx.doi.org/10.1016/S1369-5266(99)80026-0

Ohnishi N and Murata N (2006). Glycinebetaine counteracts the inhibitory effects of salt stress on the degradation and synthesis of D1 protein during photoinhibition in Synechococcus sp. PCC 7942. Plant Physiol. 141: 758-765. http:// dx.doi.org/10.1104/pp.106.076976

Park EJ, Jeknić Z, Chen TH and Murata N (2007). The codA transgene for glycinebetaine synthesis increases the size of flowers and fruits in tomato. Plant Biotechnol. J. 5: 422-430. http://dx.doi.org/10.1111/j.1467-7652.2007.00251.x

Pons R, Cornejo MJ and Sanz A (2013). Is ABA involved in tolerance responses to salinity by affecting cytoplasm ion homeostasis in rice cell lines? Plant Physiol. Biochem. 62: 88-94. http://dx.doi.org/10.1016/j.plaphy.2012.10.013

Rhodes D and Hanson AD (1993). Quaternary ammonium and tertiary sulfonium compounds in higher plants. Annu. Rev. Plant Physiol. Plant. Mol. Biol. 44: 357-384. http://dx.doi.org/10.1146/annurev.pp.44.060193.002041

Sakamoto A and Murata N (2000). Genetic engineering of glycinebetaine synthesis in plants: current status and implications for enhancement of stress tolerance. J. Exp. Bot. 51: 81-88. http://dx.doi.org/10.1093/jexbot/51.342.81

$<$ bok>Sambrook J, Fritsch EF and Maniatis T (1989). Molecular Cloning: A Laboratory Manual, 2nd edition. New York: Cold Spring Harbor. $</$ bok $>$

Shirasawa K, Takabe T, Takabe T and Kishitani S (2006). Accumulation of glycinebetaine in rice plants that overexpress choline monooxygenase from spinach and evaluation of their tolerance to abiotic stress. Ann. Bot. (Lond.) 98: 565571. http://dx.doi.org/10.1093/aob/mcl126

Wang YB, Guan LL, Xu YW, Shen H, et al. (2014). Cloning and sequence analysis of the safflower betaine aldehyde dehydrogenase gene. Genet. Mol. Res. 13: 344-353. http://dx.doi.org/10.4238/2014.January.21.2

Wani SH, Singh NB, Haribhushan A and Mir JI (2013). Compatible solute engineering in plants for abiotic stress tolerance - role of glycine betaine. Curr. Genomics 14: 157-165. http://dx.doi.org/10.2174/1389202911314030001

Weretilnyk EA and Hanson AD (1990). Molecular cloning of a plant betaine-aldehyde dehydrogenase, an enzyme implicated in adaptation to salinity and drought. Proc. Natl. Acad. Sci. USA 87: 2745-2749. http://dx.doi.org/10.1073/ pnas.87.7.2745

Wood AJ, Saneoka H, Rhodes D, Joly RJ, et al. (1996). Betaine aldehyde dehydrogenase in sorghum. Plant Physiol. 110: 1301-1308. http://dx.doi.org/10.1104/pp.110.4.1301

Xiao G, Zhang GY, Liu FH, Wang J, et al. (1995). Study on BADH gene from Atriplex hortensis L. Chin. Sci. Bull. 40: 741-745.

Genetics and Molecular Research 15 (2): gmr.15027848

CFUNPEC-RP www.funpecrp.com.br 
F.W. Wang et al.

Zhou C, Ma ZY, Zhu L, Guo JS, et al. (2015). Overexpression of EsMcsul from the halophytic plant Eutrema salsugineum promotes abscisic acid biosynthesis and increases drought resistance in alfalfa (Medicago sativa L.). Genet. Mol. Res. 14: 17204-17218. http://dx.doi.org/10.4238/2015.December.16.20

Zhou S, Chen X, Zhang X and Li Y (2008). Improved salt tolerance in tobacco plants by co-transformation of a betaine synthesis gene BADH and a vacuolar $\mathrm{Na}^{+} / \mathrm{H}^{+}$antiporter gene SeNHX1. Biotechnol. Lett. 30: 369-376. http://dx.doi. org/10.1007/s10529-007-9548-6 